\title{
Discussion on the Basic Education Development in rear Areas During the Period of Anti-Japanese war
}

\author{
Yuan Wu \\ Southwestern University, Chongqing, 400715, China
}

Keywords: The Period of Anti-Japanese war, Rear areas, Basic education

\begin{abstract}
After the Anti-Japanese war began, China's basic education which was stably developed was damaged by the Japanese imperialists, the Chinese nation's education appeared survival crisis. To cultivate excellent war talents, gain advantage in the war, and ensure the survival and development of the Chinese nation's education, the national government and western region in rear areas of the war, developed basic education jointly, which greatly promoted the basic education development in rear areas during the war and made a great contribution for the final victory of Anti-Japanese War.
\end{abstract}

\section{Introduction}

Before the outbreak of the Anti-Japanese War, although basic education in the western region had been obtained corresponding progress through exploration and practice, but it played a role in a marginalized position in the development process of the country's overall education development, and there were few communications and interactions with the regions where were developed for economy, culture and education; there were relative lack of educational resources, which restricted the further development of the western area elementary education to a certain extent,. War broke out in the western region as a rear anti-Japanese war reserves, and in support of the government, political, economic, cultural, educational and military has been a corresponding development, a large number of war-centered schools migrate to the west, a great promote the development of basic education in rear, rear basic education in the modern era has officially entered an important period of development and prosperity.

\section{Development of basic education in rear areas during Anti-Japanese War}

\section{Summary of elementary education development}

Primary school education is a fundamental component of China's overall national education. After the Nanjing national government was established, it should be clearly stated as exploration and development of basic education schools in key points in 1932-1933, the then National Government education departments have jointly developed and issued the corresponding Primary and elementary rules of law education for Primary Schools in Western Region was the development and popularization of basic education provides a corresponding system. In accordance with the mandatory requirements related to the education system, in the first decade of Sino-Japanese War broke out, the area west elementary education has been a corresponding development, but the effectiveness of education cannot be harmonized. After the war broke out, the western region a rear War, the founding of the anti-Japanese base also will form the basis of education ${ }^{[1]}$. Against this background, our national government has increased the importance of primary education in western regions, giving its strong support in terms of policy; the number and the quality of teaching rear basic primary school education have been significantly improved. The basic primary education in rear areas during the Anti-Japanese War under the influence of the government's gone through two stages of development, namely the pre-compulsory education and national education late stage.

Stage of compulsory education development

On the eve of the Anti-Japanese War, the Nanjing National Government developed scientific primary school law and regulations based on the development of basic education of China, which performed comprehensive and detailed discussion for compulsory primary education, which clearly pointed out the primary stage of compulsory education and school-age children of age. Meanwhile, in 
order to further the implementation of compulsory education in the country, the Republic of the Ministry of Education requires all provinces and can take appropriate measures according to the provincial educational development of their own work, that each region can be relatively simple to set up a two-year education, Mandarin-year primary schools, sports and math courses, the teaching of specific education using part-time education or double shifts all day; two-year primary school the appropriate additional training for citizenship, work and other educational programs, teaching double shifts fully implemented ${ }^{[2]}$. In 1935, after the Republic of China Ministry of Education to study the introduction of the Interim Measures for the implementation of compulsory education outline rear basic primary education by a two-year compulsory education has gradually developed into a four-year, orders Shanxi, Shaanxi-Gansu, Zhejiang and other 19 provinces and cities in the implementation of compulsory education, and education in accordance with the principles of staging, a two-year education will be gradually transformed into a four-year education. Installment plan with the national government supporting the implementation of the Ministry of Education has also developed a series of educational management practices, such as the division of primary school district policy, roving teaching methods, school improvement policy, to a certain extent, to further promote the Anti-Japanese War rear Primary development of compulsory education.

Stage of national education development

After the National Government issued Platform county organizations at all levels in 1939, the official implementation of the new county education system, and in the process of developing and implementing national education development derived from the Guiding Programme, a formal decision from the rear War Sichuan, Yunnan, Guizhou, Guangxi, Chongqing, Ningxia, Xinjiang etc. 19 provinces and cities in the first implementation of the new national education, in particular the implementation period 1940.8-1942.7, city and county township set up a primary focus of the center, every 3 Paul founded an elementary school, the implementation of national education, to ensure that at the end of the current education reform has been the number of children enrolled can reach more than $65 \%$ of the total school-age children. After that, the number of primary school increasing national support for the government in education policy, reform of the entire education period after technology, the actual number of children in school has been able to achieve more than the total number of society at that time 90 percent of school-age children, basically achieved within five years the popularity of the development of national education.

It should be appreciated that the rear area of basic primary education in the western region during the war to obtain the corresponding development in support of national policy, the number of pre-primary schools, primary school enrollment rates and the quality of education than the stations have been significantly improved. Particularly in the pre-war relatively good foundation for the development of education area, in support of the country during the war, the more rapid development, promoted the progress of China's overall basic education to some extent.

\section{Summary of secondary education development}

Before Nanjing National Government was established, secondary education in the western region generally used three-three system of teaching, and there was a gap compared to the primary education at that time, mainly due to the new educational system guiding spirit has not been recognized by most people, local cities and counties want actively founded school, in middle school education, but did not clear where the social implementation of the basic purpose of secondary education, although the number of high school significantly improve the quality of education high school but has lagged behind ${ }^{[3]}$. Accordingly, the Nanjing national government has also issued a corresponding education law, to a certain extent, indicates the direction of the founder of secondary education, the development of education in middle schools in the west played a relevant role.

After the war broke out, the basis of secondary education in western regions was relatively backward in a certain sense increasingly unable to adapt to with the education situation after the war. Therefore, in order to stabilize the war rear areas, to provide more relevant personnel for the war, the national government developed a series of policies and take corresponding measures committed to 
reversing the backward development of the situation in secondary education in the west area, on the secondary education in rear areas further exerting a positive impact on development.

Meanwhile, the Ministry of Education of the Republic of China in addition to actively organizing theater education institutions and schools westward during the war, but also to support the development of basic education in wartime set up a special area in the rear area of secondary education in secondary education, where the province's major rear also Republic of China Ministry of Education under the city's supervision, combined with the actual situation of the province actively take corresponding measures of secondary education development in the region. In addition, the rear interior provinces also referring to the province's high school education district set up a committee to study the development of appropriate secondary education, and select several models of secondary education in the region as an organization and convener of Education Research and Development Committee. These policies and measures have prompted some extent hinterland provinces secondary education during the war has been healthy and stable development, Sichuan, Yunnan, Guizhou and other regions on the basis of secondary education and even the front of the station has been some improvement, Shaanxi, Gansu, Ningxia and Xinjiang regions were at this stage of education made a breakthrough in the development of education has made remarkable achievements.

\section{Summary of basic education development in rear areas during Anti-Japanese War}

Although the arrival of Anti-Japanese War produced great damage to China's overall education, but objectively it also brought opportunity of development at the corresponding level for basic education in western China, so that the rear area of basic education in the national policy support, support rich educational resources obtained under certain development effectiveness. First, the overall level of development of the Rear Area during the Anti-Japanese War basic education point of view, the rear area of basic education in primary and secondary schools during the Anti-Japanese War on the number of schools and school quality have been significantly improved, but note that, although primary education has also been the corresponding development, but to enhance the overall quality of education level, the western region is not completely change the backward situation of basic education still needs further development and support ${ }^{[4]}$. Secondly, the whole range of education during the Anti-Japanese War covered rear point of view, basic education, covering almost all the provinces of the Northwest and Southwest, Northwest Shaanxi and Gansu provinces in the development of basic education in the most significant of the southwestern Sichuan and places Yunnan and Guizhou provinces basic education development strongest momentum, the war for the cause of the culture of many talents. Finally, under the influence during the Anti-Japanese War education reform, rear basic education go hand in hand showing public and private development of the situation, greatly promoted the further development of the rear area of basic education.

\section{Historical influence produced by basic education development in rear areas during Anti-Japanese War}

On the eve of Anti-Japanese War, the basic education in western China was showing quite backward trend compared to the regions where were relatively developed on economy, after entering the Sino-Japanese War of development with a relatively heavy burden. After the Sino-Japanese War broke out, the affected wartime special historical background, rear base in Western China attaches great importance to education in the country and society was a great opportunity for development, and achieved remarkable development effectiveness, not only to a certain extent, war career exerting an important supporting role, also contributed to the overall development of education in the western regions, politics, economy, culture, education post-war construction of the western region provides a rich human resources reserves.

First, the development of basic education in the rear areas played a supporting role for China's Anti-Japanese War to some extent. Anti-Japanese War greatly contributed to the development of basic education in the western region of the rear area, the development of children in the rear area of education for the Sino-Japanese War and to provide the corresponding personnel support. On the one hand, basic education rear area of the western schools respond positively Wartime education policy, 
require appropriate education on the basis of the proportion of the addition of the war teaching in the actual development of Sino-Japanese War, mobilizing students' patriotic enthusiasm, and to strengthen military propaganda. On the other hand, the western part of the primary and secondary school teachers and students of the region directly involved in the war, all aspects of transport-related talents for the cause of Sino-Japanese $\mathrm{War}^{[5]}$. Second, it helped to establish the idea of education-oriented education for national salvation. First, the development of basic education Rear highlighted the important position of the wartime development of basic education. In the social context of Sino-Japanese War, China's political turmoil, the fall of a large area of territory occurred, rear War forced the western region for the state to assume an important responsibility to nurture talent war, in the war set off anti-Japanese rear education and saving the nation the purpose of the school of the wind. Rear elementary education in the western region during this period greatly inspired the patriotic enthusiasm nationals, awakened the political consciousness of the community against imperialism and feudalism, in educational practice and trained a group of high degree of political responsibility, be able to War founding cause of dedication to the people, for the post-war nation-building and development of human resources abundant reserves, even after the founding of new China the first countries to have the majority of leaders in education rear base have received the appropriate education. Visible, rear basic education in the western region during the war, for the modernization of education in the western region to create a new situation, but also led to the sustained development of education in China to some extent. Second, it was self-creating various conditions, actively running schools, the implementation of school education. Rear primary and secondary education institutions during the war, the western region to overcome the difficult conditions, to create conditions for independent start-up related to the school, student transfer the war to the mind and spirit, to a certain extent, cause rear education for students in the form of basic education at the same time more full vitality, spirit and promote the spread of the war to provide a material basis. Finally, China's overall education plays an important role in the continuity. Rear elementary education not only saved during the war and wartime development of basic education, but also on the whole post-war development of basic education has played an important role in the foundation. Japanese imperialism launched wars of aggression in our country not only to plunder China's abundant resources and material wealth, but also to destroy the nation's precious spiritual wealth, in order to avoid the erosion of the war, primary and secondary schools to the western migration of the theater, save resources for basic education in the overall Educational Development plays an important role in the continuity. Meanwhile, the rear area of basic education has been significantly developed during the war, after the war are still part of the educational institutions and schools remain institutions in the West, to join the Western camp, basic education, level of education in the western region to enhance the integrity of exerting an important influence .

\section{Conclusions}

In summary, the basic education development in rear areas in the western region during the Period of Anti-Japanese war not only developed the lifeline of national education on the occasion of the national peril continuation, but also cultivated many young people into talents for war and nation founding during the war, and it made a corresponding contribution for the victory of the war and the founding of New China, which has a certain historical significance, and it is possible to provide a reference and inspiration for the development of China's modern education.

\section{Acknowledgments}

This paper belongs to the basic scientific research project of Ministry of Education Basic education research in Sichuan during the Anti-Japanese War, No: SWU0909675 


\section{References}

[1] Feng Li. Study on the vocational education development in rear areas during Anti-Japanese War - Centered with Sichuan, Yun’nan and Guizhou. Southwest University, 2011.

[2] Liu Jing. Study on the basic education development in rear areas during the Period of Anti-Japanese war - Centered with Sichuan, Yun'nan and Guizhou. Southwest University, 2011.

[3] Yin Li. Comparative study on the vocational education policy in southwest rear areas before and after Anti-Japanese War. Vocational education forum, 2010(19):92-95.

[4] Wang Feng. The school teachers' living conditions in rear areas during Anti-Japanese War. Hebei North University Journal (social sciences edition), 2013(6):51-55.

[5] Meng Jie. The influence of productive force development on vocational education in southwest rear areas during Anti-Japanese War. Youth Science (Teachers' edition),2014,35(7):43-44.

[6] Che Li. The mass education museum of Xikang Province during Anti-Japanese War. Southwest University for Nationalities Journal (Humanities \& social sciences edition), 2011, 32(11):210-214. 